\title{
De Stahl a Lavoisier em Portugal Setecentista
}

\section{O sistema stahliano em Portugal setecentista}

1.1. - Devotado à análise química dos mixtos, com uma tecnologia altamente baseada no uso do fogo em graus diversos, o químico farmacêutico do século XVII e inícios do século XVIII acabou por se interrogar sobre a natureza do fogo e calor e dos elementos que obtinha na resolução dos mixtos com que trabalhava. Os produtos obtidos a partir de destilaçð̃es sucessivas nem sempre se apresentavam homogéneos e muitos deles eram susceptíveis de serem decompostos. Impunha-se questionar a sua natureza. Seriam eles realmente corpos simples?

Com Van-Helmont, Descartes, Boyle, Gassendi e outros, os químicos pðem-se, uma vez mais no decorrer da História da Ciência, a hipótese metafísica da unidade da matéria. A doutrina dos cinco corpos simples dos químicos do Jardin du Roi, como a doutrina dos três princípios da filosofia química de Paracelso, chave da iatroquímica então praticada, são reformuladas e assumem uma orientação e um conteúdo significativamente diferentes. A atenção dos químicos volta-se com maior interesse para a natureza do fogo e do ar e dos demais elementos, deixando-se arrastar, com naturalidade, para os problemas sobre a natureza da combustão e das forças que dão consistência aos compostos (1).

Becher (1635-1682) dá o passo mais decisivo nessa reformulação. As suas obras Oedipus Chimicus (1664) e Physica Subterranea (1669) (2-3) rapidamente se impð̃em como dois textos base sobre os elementos, os princípios e os processos químicos. Nelas, Becher rejeita a doutrina corrente relativa aos quatro elementos de Aristóteles, o fogo, a terra, a água e o ar, afirmando que o fogo não é, de modo algum, um verdadeiro elemento e considerando que os verdadeiros princípios elementares de todas as coisas são o ar, a água e a terra. Porém, destes três, mais que elementos constitutivos, o ar é antes um instrumento de mistura e, portanto, os elementos que são realmente base de todas as coisas materiais são a agua e a terra. Da mistura da água com a terra, sob a acção do ar, resultam as estrelas, os animais, os vegetais e os minerais. A terra é a substância essencial na formação dos corpos subterrâneos.

Considerando as diferentes propriedades dos metais e outros minerais, Becher foi levado a admitir três tipos de terra: uma que explicasse a substância dos mesmos; outra, a sua cor e combustibilidade; e uma terceira, a sua subtileza, forma, odor e peso. Na Natureza existiriam pois, uma terra vitrescible, uma terra pinguis e uma terra fluida.

Não obstante o inegável paralelismo, não há uma correspondência rigorosa, nem estricta, entre estes três tipos de terra e os três princípios de Paracelso, o sal, o enxofre e o mercúrio. A filosofia dos princípios quími$\cos$ de Becher afastava-se claramente da correspondente filosofia de Paracelso (ref. 4, pg. 461).

A Fisica Subterrânea de Becher fascinou, particularmente, o químico alemão George Stahl (1660-1734) que a considerou um dos mais importantes textos químicos que jamais haviam sido escritos. Stahl analisou-a com cuidado, em pormenorizado estudo e re-editou-a, em 1703, numa edição que incluia um longo comentário de sua autoria sob o título Specimen Beccherianum (5).

Sthal identificou a terra pinguis de Becher, uma terra gordurosa, oleosa e combustível, com o princípio sulfuroso de Paracelso, responsável pela combustibilidade dos corpos em cuja composição entre. E na sequência de uma certa tradição alquímica e química, chamou a essa terra flogisto: "ego Phlogiston appelari coepi; nempe primum ignescible, inflammabile; directe atque eminenter ad calorem suscipiendum atque fovendum habile Principium» (ref. 5, pg. 39).

Para Sthal, esta terra pinguis chamada flogisto tornou-se a base dum novo sistema teórico e método de explicação de todos os fenómenos químicos, o sistema stahliano, que logo se constituiu em teoria química verdadeiramente compreensiva que dominaria quase todo o século XVIII, a que aderiram facilmente os químicos mais notáveis. Foi a celebrada Teoria do Flogisto contra a qual se viria a constituir, em árdua revolução de conceitos e princípios, o sistema de Lavoisier.

1.2 - A Historologia Médica de Rodrigues de Abreu, 1733, (6) é a defesa e introdução pronta do sistema stahliano em Portugal. Nela, o autor «depois de dar notícia de todos os systemas que tem havido na Medicina, conheceo, que o Systema Stahliano merecia preferencia entre os outros, porque conforme os seus Principos, nelle se pode dar melhor razão dos phenomenos da Natureza Humana, tanto no estado de saúde, como no tempo das enfermidades"; "por todos estes motivos tomou a resolução de explicar a Doutrina daquelle Author, e o faz na lingoa Portugueza» (ref. 6, Aprovação de Francisco Teixeira Torres). No longo Prefácio que escreveu para esta obra, Martinho de Mendonça declara: «pelo Author conhecerá o Orbe litterário que sem razão imaginam os Estrangeiros que os Portuguezes todos pelo que toca à Filosofia, nos conservamos na escura barbaridade de termos abstractos, a que não corresponde idea alguma real, quaes por meyo do tempo nos introduziraõ os árabes. Não são poucos os que neste Reyno buscaō a melhor Fysica na curiosa observação dos effeitos naturaes, e na sagaz inda-

\footnotetext{
'Departamento de Química - Universidade de Coimbra, 3000 Coimbra.
} 
gação das suas causas». E a terminar: «não somente he V. m. o primeiro que em Portugal segue o Systema Stahliano, mas também o primeiro que, dando à luz a sua Historologia Medica, com nobre impaciencia se afasta da Filosofia Escholastica, que neste Paiz he o forte da authoridade Peripatética) (ref. 6, Proémio de Martinho de Mendonça).

Ponderando os requisitos necessários e precisos para um Médico Prático no exercício clínico, Rodrigues de Abreu debruça-se demoradamente sobre as doutrinas dos Gregos, Ârabes, Indos, Chineses, Paracelso, Severino, Crollius, Van-Helmont, Tachenius, Sylvius, Willis, Descartes, Gassendi, Hoffman, Boerhaave, Andry, Bartholomeo Moor e Leibnitz para se fixar no sistema de Stahl que considera o mais verosímil de todos pelos «sólidos, experimentaes e racionaes fundamentos em que se estriba» (ref. 6, pg. 159). Quase idolatricamente, ele enumera todas as obras publicadas, ano a ano, por Stahl e refere uma longa lista de 57 escritores que seguiram a sua doutrina, uma doutrina que, segundo ele, assenta na observação e contemplação das três seguintes circunstâncias: (i) - a matéria do corpo humano e sua mixtão; (ii) - a vida ou conservação do corpo mixto; (iii) - o modo com que se conserva o mesmo corpo tanto pelos movimentos vitais ordinários como extraordinários (ref. 6, pg. 159).

$\mathrm{Na}$ consideração destas circunstâncias, Rodrigues de Abreu tem para si que o "Médico não he ministro do Macrocosmos, mas do Microcosmos») pelo que tem por inútil para o exercício da Medicina o procurar saber-se se a «matéria prima he um quid extenso ou hum conglobado de átomos summamente miúdos", como por inútil tem «aquellas célebres e subtis questoens da Forman, as controvérsias sobre se a privação deve ou não entrar no número dos Princípios Fysicos, as disputas sobre «as subtilezas da luz tanto torcida como quebradan, e muitas outras controvérsias de que se ocupava o ensino peripatético (ref. 6, pp. 164-165). Interessado tão somente nos «phenomenos que se offerecem no homem", o médico deve, sim, conhecer bem a Botânica, a Anatomia e, sobretudo, a Química (ref. 6, pp. 167-171).

Depois duma breve referência à Química dos Antigos e da Idade Média, fixa-se o autor no que chama a Quimica Nova, a química posterior a Paracelso, na sua tripla orientação: a Alchimia, a Chymica Fysica - Mecânica Racional e a Chymica Pharmacêutica (ref. 6, pg. 176). A medicina importa não só a prática química que se ocupa da «attenta observação de todos os fenómenos que vere et directe pertencem ao fim salubre", como também aquela que se debruça racionalmente sobre a natureza dos fenómenos observados. Uma e outra devem, todavia, total fidelidade à experiência: "faça-se primeiro à experiência, e depois se seguirá o juizon (ref. 6, pag. 196).

Todos os corpos são "constituidos de terra subtil, mais ou menos disposta para a salsugem, de óleo ou Pinguedo e de água" (ref. 6, pg. 190). Estes mesmos três elementos são os constituintes dessa «pulcherrima fábrica» que é o Corpo Humano que uma vez devidamente aparelhada, com todas as suas partes devidamente dispostas na sua ordem, pode receber o Agente Vital, a Alma Racional ou Princípio Interno do movimento, que dela faz uma máquina "sui generis» dotada de uma especificidade tal que não há outra que se lhe iguale na Natureza: uma máquina capaz de se nutrir e crescer; uma máquina capaz de produzir por geração uma outra a si igual, propagando-se por este modo a sua espécie; uma máquina dotada de Entendimento,
Vontade, Apetite, eleição do bom e outras coisas semelhantes, capaz de determinar o seu próprio movimento por deliberaçøes do seu alvedrio, ficando-lhe todas arbitrárias (ref. 6, pp. 201-270).

Todas as operaçð̃es desta pulcherrima máquina se encaminham a um certo e determinado fim com que se consegue a saúde, o que todo obra o Princípio Activo pela proporção ou improporção de seus movimentos internos e externos.

Seduzido pelo animismo stahliano, Rodrigues de Abreu considera, tal como o mestre (ref. 4, pp. 463-469), de pouca utilidade para o fim clínico e químico, o estudo da matemática, da história ou da geografia, ciências que «embora possam servir de ornamento ao médico, nada fazem para conservar e restituir a saúde» (ref. 6, pg. 186). Na química experimental encontrará o investigador o verdadeiro e real conhecimento das coisas.

\section{O sistema de Lavoisier em Portugal setecentista}

2.1 - Quando, em 1772, o Marquês de Pombal procedeu à Reforma da Universidade de Coimbra, dotando-a de novos Estatutos, em França, Lavoisier dava os primeiros passos nos seus trabalhos que o levariam à reformulação profunda da química como ciência.

Nesta Reforma da Universidade Portuguesa, os Estatutos instituem a química como disciplina autónoma que integra o quarto ano do Curso Filosófico, com o objectivo de «indagar as propriedades particulares dos corpos: analysando os Princípios delles: Examinando os Elementos de que se compoem: e descubrindo os effeitos e propriedades relativas, que resultam da mistura e applicação intima de huns aos outros» (7).

No plano teórico, o programa geral dessa disciplina é definido pelos mesmos Estatutos como devendo conter: (i) um resumo abreviado da história desta ciência, mostrando a origem que teve, os progressos que fez, as revoluçðes, sucessos e decadência que conheceu; o descrédito com que a cobriram os Alquimisitas; e, finalmente, a sua restauração, nos últimos tempos, para bem das artes que dela dependem; (ii) uma ideia geral das propriedades relativas das substâncias que entram na composição dos corpos sob acção da Affinidade que leva umas substâncias a unirem-se intimamente entre si, ao mesmo tempo que repugnam a contrair uniâo com outras; (iii) um exame das substâncias que constituem espécies particulares, começando pelas mais simples e passando delas às mais compostas, isto é, começando pelas substâncias salinas, em geral e em particular; mostrando as propriedades e afinidades dos ácidos com as terras absorventes, com a água e o flogístico; e explicando as particulares observaçðes dos Alkalis fixos e voláteis; dos sais neutros; dos ácidos vitriolicos e nitrosos; das substâncias metálicas; e das substâncias oleosas em geral e em particular; tratando dos óleos minerais, vegetais e animais; das preparaçōes e dos usos deles; (iv) exame das diferentes operaçōes que se empregam na análise das substâncias animais, vegetais e minerais, como são as destilaçð̄es, emulsð̄es, dissoluções, etc...; (v) explicação da Tábua das afinidades como recapitulação artificiosa das verdades fundamentais desta Arte.

As Liçōes Theoréticas deveriam ser acompanhadas de Liçōes Práticas, no Laboratório, onde o Professor deveria mostrar aos seus Discípulos os Processos quimicos conhecidos na Arte, tratando da Análise e Operaçōes sobre os diferentes produtos dos três reinos da Natureza, sem que fizesse deles meros expectadores, obrigando-os sim a trabalhar nas mesmas Experiências, 
para se formarem no gosto de observar a Natureza e contribuirem por si mesmos ao adiantamento e progresso desta ciência, «a qual não se enriquece com sistemas vãos e especulaçōes ociosas, mas com descobrimentos reaes, que não se acham de outro modo senão observando e trabalhando" (8).

Expressamente para este fim, mandou o Marquês construir um Laboratório Chimico apropriado.

Instituída como disciplina autónoma no Curso da Faculdade de Filosofia, apontando, programaticamente, para "descobrimentos reaes», sem "divagaçð̌es por sistemas vãos e especulaçð̃es ociosas", a Química em Portugal, no último quartel do século XVIII, segue a par e passo os progressos desta ciência além fronteiras, procurando também ela dar o seu contributo para a resposta às principais questð̄es que então se punham no seu domínio. Servida por homens nela totalmente empenhados, com Domingos Vandelli (1730-1816), Manoel Joaquim Henriques de Paiva (1752-1829), Thomé Rodrigues Sobral (1759-1829) e Vicente Coelho da Silva Seabra Telles (1764-1804) na vanguarda, desenvolve-se, de início, fiel à teoria do Flogisto em que as Institutiones Chemiae de Spielmann (9), primeiro, e os Fundamenta Chemiae de Scopoli (10) depois, são os textos preferidos. Mas acompanha rapidamente o evoluir da química pneumática e do oxigénio da Escola de Lavoisier. Do ponto de vista prático, é uma química profundamente empenhada no estudo do comportamento dos gases, dos fenómenos de combustão e fermentação, da natureza do calor e da água, das afinidades relativas dos diversos elementos, da nomenclatura e classificação, etc. No Laboratorio Chimico procedia-se sem cessar a preparaçð̃es e investigaçōes as mais diversas, relacionadas com todo esse tipo de questōes (11-12).

2.2 - Em 1783, Manoel Henriques de Paiva que fora Demonstrador e Mestre no Laboratorio Chimico da Universade de Coimbra até 1779 , ano em que, a convite do Rei, foi viver para Lisboa como Médico da Corte, no exercício de Professor de Química Farmacêutica que aí leccionava, publicou «a primeira obra chimica que em nossa linguagem sahe à luz») - como se lê na Dedicatória ao Senhor Diogo Ignácio de Pina Manique nela inserta - os Elementos de Chimica $e$ Farmácia (13).

Como o próprio autor refere no Prefácio, neste seu livro expð̋ ele um conjunto de preceitos, regras e experiências, que formam o corpo da doutrina de alguns dos mais célebres químicos de então, principalmente de Scopoli. E uma obra sem grande originalidade, de índole inteiramente flogística, desejosa de ser útil aos interesses da saúde e do comércio deste Reino e suas Conquistas (ref. 13, Dedicatória).

2.3 - Entretanto, em 1788, publicava Vicente Coelho de Seabra, depois deter publicado uma Dissertação sobre a Fermentação em Geral e suas Espécies (Coimbra, 1787) e uma Dissertação sobre o Calor (Coimbra, 1788), o primeiro volume de um Manual institulado Elementos de Chimica (14) que viria a completar com a publicação, em 1790, de um segundo volume. Embora dedicado à Sociedade Literária do Rio de Janeiro (Brasil), e nunca tendo sido adoptado como Manual no Curso de Química ministrado na Universidade de Coimbra, este livro é, sem dúvida, a expressão mais fiel do estado da ciência química em Portugal ao terminar do século XVIII.

Nele se expð̄em e defendem as teorias de Lavoisier, apresentando, todavia, em mais que um ponto, notável originalidade no uso da nova química para interpretar os fenómenos químicos então conhecidos e ainda não cabalmente explicados. O próprio Manual chama a si originalidade quer no arranjo que adopta na exposição dos diversos assuntos de que trata, quer em algumas explicaçőes teóricas com que avança. A título de exemplo, mencione-se a análise que apresenta, ao falar das afinidades químicas, em que reconhece o carácter dinâmico do equilíbrio entre espécies em solução e a possibilidade desse mesmo equilíbrio ser deslocado numa ou noutra direcção por alteração da proporção dos reagentes presentes; ou ainda, o reconhecimento do conteúdo térmico dos sistemas químicos, com referência explícita a calores latentes ou calores especificos de compostos na sua relação com o calor específico das correspondentes componentes (12).

Levar-nos-ia longe o exame promenorizado desta obra de Vicente de Seabra que reputamos de pioneira no dominio da Revolução Química levada a efeito por Lavoisier e seus sequazes. Para além da sua originalidade, ela é prova da rápida disseminação e influência da nova química pneumática, a química a que haviam aderido decididamente e que cultivavam com paixão os químicos portugueses ao terminar do século.

\section{Referências:}

1 - Helene Metzger, Les Doctrines Chimiques en France du début du XVII. è la fin du XVIII.e sécle. Pt. I, Paris. Presses Universitaires de France. 1923, cp. VI, pp. 339-420.

2 - J. J. Becher, Oedipus Chimicus Obscuriorum terminorum et principiorum misteria aperiens et resolvens, 1664, in J. J. Manget Bibliotheca Chemica Curiosa (Geneva, Chouet et al., 1702).

3 - J. J. Becher, Physica Subterranea, 1669, Leipzig, Joh. Ludov. Gleditschium, 1703.

4 - A. G. Debus, The Chemical Philosophy, vol. II, New York, Science History Publications, 1977.

5 - G. E. Stahl, Specimen Beccheriamum Apêndice de Physica Subterranea de Becher editada em Leipzig, Joh. Ludov. Gleditschium, 1703.

6 - Joseph Rodrigues de Abreu. Historologia Médica, Fundada e Estabelecida nos Princípios de George Ernesto Stahl, Lisboa Occidental, Officina da Música, 1733.

7 - Estatutos Pombalinos da Universidade, Liv. III, Pt. III, Tit. III, cp. II, 6.

8 - Estatutos Pombalinos da Universidade, Liv. III, Pt. III, Tit. III, cp. IV, 1-13.

9 - Jacob Reinboldi Spielmann, Institutiones Chemiae - Praelectionibus Academicis Adcommodatae, Argentorati, Johannem Godofredum Brauerum, 1766.

10 - Joannis Antonius Scopoli, Fundamenta Chemiae - Praelectionibus Publicis acommodata, Praga, Apud Wolfgangum Gerlb, 1777.

11 - A. M. Amorim da Costa, (a) Primórdios da Ciência Química em Portugal, Lisboa, Instituto de Cultura e Lingua Portuguesa, 1984; (b) Thomé Rodrigues Sobral (1759-1829), a Química ao Servi;o da Comunidade in História e Desenvolvimento da Ciência em Portugal, Academia das Ciências, Lisboa, 1986, pp. 373-401; (c) Doningos Vandelli (1730-1816) e A Cerâmica Portuguesa, idem, pp. 354-371); (d) A Universidade de Coimbra na Vanguarda da Química do Oxigénio, idem, pp. 403-416.

12 - A. J. Andrade de Gouveia, (a) Químico esclarecido luso-brasileiro: Vicente de Seabra (1764-1804) in Membrias da Academia das Ciências de Lisboa, vol. XXI, 1976/77, pp. 7-35; (b) Vicente de Seabra and the Chemical Revolution in Portugal in Ambix, vol. 32, 1985, pp. 97-109.

13 - Manoel Joaquim Henriques de Paiva, Elementos de Chimica e Farmácia, Tom., I, Lisboa, Academia Real das Sciencias, 1783. 14 - Vicente Coelho da Silva Seabra Telles, (a) Dissertação sobre a Fermentação em Geral e suas Espécies, Coimbra, Real Impressão da Universidade, 1787; (b) Dissertação sobre o Calor, Coimbra, Real Impressåo da Universidade, 1788; (c) Elementos de Chimica, Coimbra, Real Officina da Universidade, 1788 (Part I) e 1790 (Part II). 